\title{
Development Mode of Low Level Exhibition Tourism Derivatives and the Influences on Tourism Effect
}

\author{
Ting Zhao \\ Qinghai University School of Finance and Economics, Xining City, Qinghai Province 810016, China.
}

Keywords: Low Level, Development Mode, Tourism Derivatives, Tourism Effect, Influences.

\begin{abstract}
This paper discusses the development mode of low level exhibition tourism derivatives and the influences on tourism effect. With the development of science and technology, the human activity scope by land and sea gradually extend to the air space and outer space. Over land and sea resources and to carry out economic activities form the agricultural economy, basic industrial economy, Marine economic form. With the development of aviation, aerospace science and technology, human activity is more and more freedom in the air, the ability of development and utilization of air resource is more and more strong, that the scale of the corresponding economic activities and its effect on the human production and living is becoming more and more. This paper conducts the systematic analysis of the corresponding research that will enhance the mode of current tourism condition.
\end{abstract}

\section{Introduction}

Low travel generally use fly straight, and the speed faster, it greatly shortens the time spent for the trip. At the same time, because the general aircraft such as helicopter landing is very convenient, with tens of square meters of flat space, even top tall buildings can be used as a landing platform. Therefore, with the aid of helicopter shuttle between the destination of tourists and can be quickly, saves time, and reduce the economic and the energy consumption in the journey. Usually, helicopters, generally at about 8 people, the number of passengers not only can provide regular tour routes for the individual service, guarantee high attendance, could also provide small tourist groups to charter flight service that meets with the high-level needs of business travel team [1-2].

Under the macroscopic background of low-altitude airspace and the opening to the outside, general aviation rapid infiltration and expansion to other industries, low general aviation and tourism is the combination of the tourism industry, is the inevitable result of the shipping industry chain extension in the field of tourism. Low tourism is also called general aviation which is within the scope of the low-altitude airspace use the civil aircraft is engaged in the outside of the public air transport business, sightseeing, leisure, entertainment and other forms of tourism activities. For better analysis, we take the Hainan as the example and conduct the SWOT analysis for discussion.

- Threat. In recent years, the country's economic rapid development, people's living standards continue to improve, economic incomes go up, continue to fall the cost of the air travel, take a long flight is no longer a luxury thing, therefore, the domestic many tourists to travel target in the abroad that may influence the performance of the tourism effect.

- Advantage. Seagirt island province of Hainan has wide low-altitude airspace and superior big sea, low-flying lead advantages of the safety, convenience, almost all of the aviation tourism projects: hot air balloon, airship, helicopters, paramotor, glider can be conducted in Hainan, so as to lay the land, sea and air three-dimensional tourism landscape.

- Disadvantage. Air travel industry is a technology capital intensive industry, has a high demand for the talent, surrounding air travel projects carried out such as: small aircraft manufacturing, maintenance, training, service, research and development requires a lot of aviation technology and the corresponding service personnel [3].

Tourism itself inherent attribute determines the tourism experience will be popular in the era of experience economy as coruscate gives dazzling light. In order to give experience economy brings the new connotation of the tourism, tourism as a basic "cell" is called for the tourism products into the 
"experience" we need connotation as make tourism products to keep pace with the times. So far, the academic circle has not been able to put forward a widely recognized can call set economic activity in the form of economic measure, this is this article will low economy as a kind of economic form and leave a space is put forward. As around the low-altitude airspace resources and low level of climatic resources and air resources and carry out a kind of economic activity, the formation and development of low economy is the result of the development of industrial civilization. Low economic industrial activity in the industrial economy can be found in the roots, so from a certain perspective with the low economic should belong to the part of the industrial economy.

\section{Our Proposed Methodology}

Tourism Derivatives Analysis. In the context of modern perceptual consumption make public, color has surpassed the traditional visual elements, such as text, lines as the main medium of visual message in today's society. Artists through color resort to emotional expression, businessmen use color to color marketing consumers get aesthetic experience by color. Color, has now become most contemporary public art design of expressive art elements. The relationship between tourism industry and color is becoming more and more closely. The figure one demonstrates the sample pattern.

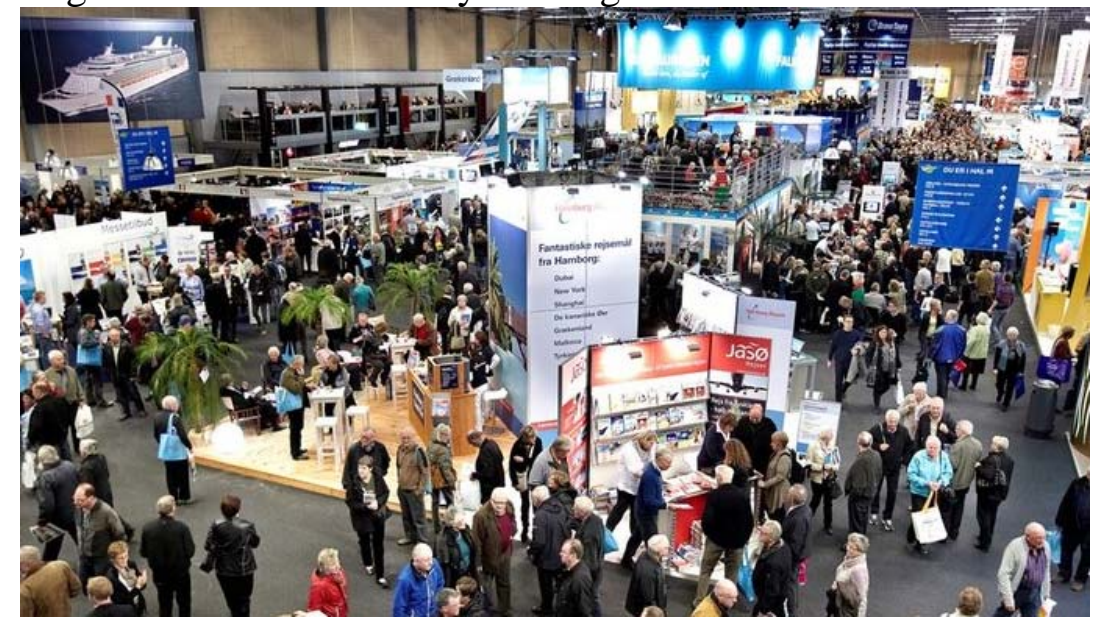

Fig. 1 The Demonstration of the Tourism Derivatives

The popularization of art derivatives, and promote the art to the public, the art is no longer confined to the museum, art galleries that no longer stay on the wall, cases, no longer stop collection, transfer function. This paper based on the concept of art derivatives, the analysis of the conditions, types and characteristics, combined with case of the art derivatives markets at home and abroad, discusses in the contemporary art derivatives the role and value of human life [4].

Tourist art derivatives refers to with the development of tourism industry to form a commemorative products with tourism regional cultural characteristics, usually timely, portability, aesthetic, and the characteristics of the arts and basic crafts. Perceptual consumption of social background, the people's choice of travel art derivatives are no longer stay in the use value of material goods, and pay more attention to the symbolism of the goods, pay attention to goods and emotional associations of tourist sites, such as memory, pleasure, cultural characteristics such as spiritual symbol value.

Art derivatives have narrow and broad. Special art derivatives, refers to the artist's works of art or artistic value of heritage as a prototype, use the methods such as copy, divert to carry on the design and manufacture of the goods. Visible, narrow art derivatives have a clear art prototype this artwork is usually recognized artists, or the heritage of art value. On the basis of art prototype, using replication technique that can be made into a limited edition and the limited edition art prints. Use the technique of embezzlement, art graphics and modelling of the prototype can be implanted into different items, with art derivatives. Through the analysis of the concept of art derivatives, we can respectively from narrow and broad grasp the core of art derivatives, the core of the special art derivatives are works of art, and the core of the generalized derivatives of art is art. But both based on 
art and based on art, art derivatives is the essential attribute of its commodity prices of the goods while the value of art can be converted to the art derived for the goods and the corresponding services.

The Tourism Effect Analysis. Study tourism from the perspective of sociology, should first clear how to recognize the nature and features of tourism, and on this basis to travel under a clear definition. The sociological research on social behavior and the social psychology think that human activities are caused by motivation, it dominate people's behavior. Motivation to some kind of need, when people have some needs as nervous or anxious state psychologically that become an inner driving force, thus producing motivation. Regional tourism image is the impression and comprehensive evaluation for tourism destination as a whole, is the tourist attractions and tourism attraction as the core content of generalization based on rational analysis after poetic form of an image, in this and Chinese traditional literature has a considerable resemblance pictorial synthesis, especially in the depiction of the pastoral landscape, ancient prose poems still has enlightenment significance for basic regional tourism image research. Over time, however, regional natural and humanistic landscape all the great changes, and a new era of connotation and significance of and nature of emerging ecological tourism development, and the use of new ideas to the development trend of the culture tourist resources.

Tourism is the result of cognition and learning. All in human society, the human behaviors contain some form of learning. Need is the need of innate human exploration, almost everyone from birth is showed. In addition to exploring the basic drive, most people in travel behavior motivation is by cognition, learning as is learned. Due to the needs and motivation can be learned, made it possible to travel behavior not only, and make the tourism as these needs and motives of the acquisition has not learned, or in a new way of acquisition and the current research can be organized as follows.

- We want to model the tourist experience of happiness, we should insist on the difference, participatory, the authenticity, challenging the four principles. Shape difference through the analysis of the differences between the uniqueness of the project for core tourists brings fresh feeling meets the personalized requirements. Participation, by the body and spirit of tourists to participate in the experience of tourists to the scenic spot is more profound and vivid.

- Travel experience is the hardcore of tourism phenomenon as the tourism experience research would constitute the tourism research one of the most fundamental and most basic, the most capable derivative field of an object of tourism experience study that will have the mission of promoting tourism subject independent.

- Scene is "love" and "scene" joint, affection is the main body, scene is the object, one is feeling into the scene, the second is for spirit third it is to want finally is to reach the scene. Experience design should be on the premise of the participation of consumers, consumer experience as the core, in the end make consumers feel good experience in the activities.

Level Exhibition Tourism Principles. For a long time, influenced by basic low-altitude airspace restrictions and so on, our country shipping industry development is relatively slow there is a big gap with foreign. In recent years, countries have issued a series of general positive policy, gradually open low-altitude airspace and the shipping industry as a national strategic emerging industries and open policy window for the development of shipping industry. The economic development of our country into a new growth cycle, moderate growing income class rise above also has given rise to the factors, such as navigation, especially high-end services, navigation tourism industry segment of the market demand. In good policy and market demand of driven by domestic many areas are beginning to try to development of shipping industry, formulate the corresponding development plan. Among them, the navigation is considered as local gathered popularity of tourism, increase consumption, promote the important carrier of industrial convergence, has been given enough attention in the planning [5].

Navigation tourism has the following characteristics. First, the uniqueness as navigation to tourism culture and navigation experience as the core. Aviation characteristics are the biggest characteristic of navigable tourism, as well as its most powerful attraction. Different from the other tourism products, navigation tourism can provide the way of "flying" tour and sightseeing experience have the strong uniqueness. Second, the experience compared with other tourism products navigation of participatory tourism products and experience more, on the one hand, this is because the navigation 
tourism relying on navigable core of aviation culture resources have more solid backing has strong experience.

For the more in-depth analysis, we summarize the level exhibition tourism as follows. (1) In the airline industry for industrial tourism resources. Aviation industry tourism factory in general aviation manufacturing enterprises as the main tourism resources, including the aviation museum, air, and the dynamic and static aircraft to carry out the visit, sightseeing, experience, shopping and other tourist activities, is a new type of tourism in integrating knowledge and leisure products. (2) To the airport for aviation tourism destination. Airport to travel to the airport as a tourist destination to airport facilities, the surrounding natural environment or special aviation history background and carried out, including visit simulated flight, the aviation museum, science and technology and traditional culture, natural scenery, shopping, eating a new kind of tourism activities, such as specific patterns include: resources for the airport facilities use the facilities of the airport, such as the observation deck, ramp, etc., to carry out the passenger's observation or interactive tourism activities. (3) By means of general aviation in the low to go sightseeing. General aviation tourism mainly refers to the air, mainly using general aircraft (such as helicopters and small private plane or hot air balloon and glider, etc.) of the natural scenery or cultural history landscape close viewing, include flight and aviation sports.

\section{Conclusion}

In this paper, we analyze the development mode of the low level exhibition tourism derivatives and the influences on tourism effect. Developed countries in Europe and the US which is based on aircraft carried out large-scale tourism activities for decades, developed air transport network and rich and colorful air travel experience project for the development of the leisure and recreation industry has injected vitality. In our country, with the opening of the low-altitude airspace and development of national economy got started in domestic air travel in recent years, many provinces and cities and regions have developed air travel to start and promote transformation and upgrading of the tourism industry in practice. With this theoretical perspective, we propose our unique idea on the low level exhibition tourism derivatives and the influences on tourism effect that is innovative. In the later and further research, we will review more research for further optimization.

\section{References}

[1] Jin, Xin, and Karin Weber. "Developing and testing a model of exhibition brand preference: the exhibitors' perspective." Tourism Management 38 (2013): 94-104.

[2] Wu, Rong, and Mu Zhang. "Research on the tourism effect and marketing strategy of convention \& exposition industry: A case study of Shenzhen City of China." Journal of Service Science and Management 6.2 (2013): 151.

[3] Lopes, M. M., et al. "What to see in Paris: a tourist guide for geologists at the 1878 Universal Exhibition." Revista Iberoamericana de Turismo (RITUR) 5.2 (2015): 48-62.

[4] Rogerson, Christian M. "The uneven geography of business tourism in South Africa." South African Geographical Journal 97.2 (2015): 183-202.

[5] Hahm, Jeeyeon Jeannie, et al. "The relationship between sense of community and satisfaction on future intentions to attend an association's annual meeting." Tourism Management 52 (2016): 151-160. 